\title{
Interactive comment on "Response of water use efficiency to summer drought in boreal Scots pine forests in Finland" by Yao Gao et al.
}

\section{Anonymous Referee \#3}

Received and published: 9 October 2016

Currently, global carbon and water cycles as well as the associated carbon-water coupling relationships are receiving more and more attentions in this research field. Particularly under the changing climate, how extreme climate events affect the carbon sequestration of terrestrial forests directly related to the future climate projections. This study aimed to reveal the responses of ecosystem water-use efficiency to summer drought in northern Europe, which will also enrich this hot topic. The work is well organized with clear structure. However, plenty of questions still need to be solved.

Major comments:

Printer-friendly version

1. In the part of "Introduction", the authors used a lot of sentences associated with ecosystem water-use efficiency, such as WUE, EWUE, and IWUE. Moreover, they want to express the potential effects of drought on different WUE expressions. I strongly sug- 
gest the authors to explain the differences of various WUE definitions, and the reasons adopted in the present study. Then, the authors used many phrases to describe soil water status. However, it is crucial that how do they define the droughts, especially severe or moderate.

2. In the part of "2.5 Soil Moisture Index (SMI)", the authors used SMI derived from simulated soil moisture and soil parameters in JSBACH to define soil moisture conditions. It may lead to the uncertainty owing to the model performance and the results in this study. Then, why not validate the accuracy of the modeled data. The SMI results are also classified as severe drought, moderate drought, mid-range, moderate wet and very wet. However, only 11-year dataset for Hyytiala and 8-year dataset for Sodankyla, which may be not enough for drought analyses.

3. In the part of "Results and Conclusion", the authors concluded that based on observed data, the ecosystem level water use efficiency (EWUE) showed a decrease only during a severe soil moisture drought at Hyytiälä, whereas the inherent water use efficiency (IWUE) increased when there was a severe soil moisture drought at Hyytiälä and a moderate soil moisture drought at Sodankylä. However, on one hand, this study is based on "no severe soil moisture deficit at Sodankylä during the study period", on the other hand, it seems to be a lack of persuasion. Maybe more data need to be supplemented to enrich the objectives of this study.

4. In the part of "Discussion", I suggest the authors to supplement the uncertainties of SMI, which is used as drought indicator of soil water. In addition, a lot of biotic and abiotic factors controls the differences of GPP, ET, WUE of the two forest sites. So, how do they directly compare the effects of drought on Scots pine forest under different local environmental conditions. Apart from this, I think in northern Europe such as Finland, temperature anomaly may be more sensitive than drought.

Minor comments:

Printer-friendly version

Discussion paper

1. P1 L13 \& L23 "at daily time scales" should be changed to "at the daily time scale". 
2. L15-L18 This long sentence is too tedious. Please reconstruct it.

3. P2 L37 Terrestrial plants assimilate carbon dioxide (CO2)...

4. L59 EWUE is broadly adopted as a surrogate for WUE due to data availability. Why? This expression is abrupt without explanation.

5. L65 It is inappropriate to cite the paper of Reichstein et al. 2002. Ecosystem water-use efficiency of gross carbon uptake decreased during the drought, regardless whether evapotranspiration from eddy covariance or transpiration from sapflow had been used for the calculation.

6. P3L90 Lack of the information on forest ages between the two flux sites.

7. P4L112 "For our analysis, daily values of GPP and ET fluxes were calculated as daily sums of half-hourly values and only good quality gap-filled data were used." It is confusing. How do they guarantee the comparability of different days?

8. P4L131 Crammer mistakes. "The models of Farquhar et al. (1980) is used for photosynthesis of C3 plants."

9. P6L188 "However, process-based ecosystem models can be used to reveal plant physiological processes by separating evaporation and transpiration." Please cite the associated references.

10. P9L311 "The consequence of decreased ET due to soil moisture drought would be increased atmospheric VPD, which in turn accelerates stomatal closure..." Please reconstruct it.

11. Please specify the time scale of data used in the figures. In addition, the data points are too dense. It is hard to extract useful information from the merged figures.

12. In Figure 4, many values of WUE at the daily time scale exceed $10 \mathrm{~g} \mathrm{C} \mathrm{kg-1} \mathrm{H} 2 \mathrm{O}$, especially for simulated results of EWUE and IWUE. Do you think it is rational or just statistical?

\section{Discussion paper}


Interactive comment on Biogeosciences Discuss., doi:10.5194/bg-2016-198, 2016.

Interactive

comment 